\title{
Histological Subtyping of Carcinoma Breast and Analysis of Ki67 Expression: A Single Institution Study in Northern India
}

\author{
Dr. Garima ${ }^{1 *}$, Dr. Vijay Verma ${ }^{2}$, Dr. Lalit Kishore ${ }^{3}$, Dr. Yamini Verma ${ }^{4}$
}

\author{
${ }^{1}$ Assistant Professor, Department of Pathology, Dr. S.N .Medical College, Jodhpur Rajasthan India \\ ${ }^{2}$ Associate Professor, Department of Surgery, Dr. S.N .Medical College, Jodhpur Rajasthan India \\ ${ }^{3}$ Assistant professor, Department of Surgery, Dr. S.N .Medical College, Jodhpur Rajasthan India \\ ${ }^{4}$ Post graduate student, Department of Pathology, Dr. S.N .Medical College, Jodhpur Rajasthan India
}

DOI: $10.36347 /$ sjams.2021.v09i01.015

| Received: 02.01.2021 | Accepted: 13.01.2021 | Published: 16.01 .2021

*Corresponding author: Dr. Garima

Abstract

Breast cancers are widely prevalent in females worldwide. Diagnosis and prognosis of carcinoma breast is effectively facilitated by the analysis of various hormone receptors and certain biomarkers. Ki-67 is an important proliferaive biomarker which is a nucleoprotein used for predicting these cancers. This study was carried out to review the distribution of histological subtypes and pattern of Ki-67expression in them. A part retrospective and part prospective study was done on a total of 59 cases of carcinoma breast. All stained slides were reviewed and the morphological diagnosis based on $\mathrm{H} \& \mathrm{E}$ staining was considered. For Ki-67 immounohistochemistry, representative sections from paraffin blocks were taken on poly- Llysine coated glass slides.Most common histogical subtype in our study was invasive ductal carcinoma followed by invasive papillary carcinoma.Ki67 score was maximum in metaplastic carcinoma followed by IDC with sqouamous metaplasia. Also ductal carcinomas had more ki67 proliferation activity than lobular ones. Further studies on large samples are required to correlate the Ki-67 to histological subtypes of breast cancer and to consider it as a significant prognostic factor of breast cancer.

Keywords: Breast cancer, immunohistochemistry, Ki-67 antigen, prognosis.

Copyright $\odot 2021$ The Author(s): This is an open-access article distributed under the terms of the Creative Commons Attribution 4.0 International License (CC BY-NC 4.0) which permits unrestricted use, distribution, and reproduction in any medium for non-commercial use provided the original author and source are credited.

\section{INTRODUCTION}

Breast cancers are widely prevalent in females worldwide. Histological types refer to the growthpattern of the tumours. The histological diversity of adenocarcinomas in the breast has long attaracted pathologists, who have identified specific morphological and cytological pat-terns that were consistently associated with distinctive clinical course and outcomes. The commonest type of breast carcinomas the so-called invasive ductal carcinomas not otherwisespecified (IDCNOS) or of no special type (IDC-NST)[1], which is a diagnosis of exclusion and comprises adenocarcinomas that fail to exhibit sufficient characteristics to warrant their classification in one of the special types. Although grade identifies prognostic subgroups among special types of breastcancer, some entities that are by definition of high histologicalgrade have a relatively good prognosis (eg.medullary carcinoma)[1]. Diagnosis and prognosis of carcinoma breast is effectively facilitated by the analysis of various hormone receptors and certain biomarkers. Ki67 is a monoclonal antibody directed against a nonhistone bound nuclear protein present only in proliferation cells. The immunostaing of malignant tumors with low and high proliferation rates showed that the number of tumor cells stained with Ki-67 coincided with estimated proliferation rates of the tumors [2]. The exact determination of percentage of proliferation cells in neoplasia is of prognostic significance and may also be important for the choice of appropriate treatment. Immunostaining with $\mathrm{Ki}-67$ has also been used in breast tumors. There have been quite a few studies which have tried to correlate Ki-67 immmunostaining with other indicators of prognosis and have also found it to be an independent prognostic marker in these tumors [3]. Although it is reasonably well established that $\mathrm{Ki}-67$ positivity is an independent predictor of ultimate prognosis and course of disease and its recurrence many lacunae exist. These studies in our own population are very scarce. As it is widely accepted that cancer management should be according to loco-regional profile and treatment strategy should be devised accordingly, however no large-scale cancer registry is available developing countries. So ki67 may serve as a useful marker in tailoring treatment regimen as response to chemotherapy may be altered by the proliferative activity of cancer cells [4]. Our study was aimed to study histological profiles and pattern of ki67 expression in breast cancer subtypes. 


\section{SubJECTS ANd Methods}

This study was carried out in Department of pathology, Vardhman Mahavir Medical College and Safdarjung Hospital, New Delhi. A part retrospective and part prospective study was done on a total of 59 cases of carcinoma breast.Representative paraffin blocks of Modified Radical Mastectomy, lumpectomy or biopsies of carcinoma breast were included for the study.

\section{ExCLUSION Criteria}

1. All the patient's blocks with breast tumors other than carcinoma breast.

2. Tissue blocks with extensive necrosis of hemorrhage.

3. Tissue section with inadequate study material.
Micron thick sections were cut for $\mathrm{H}$ \& $\mathrm{E}$ Staining, and for Ki-67 immunohistochemistry, section were on poly- L-lysine coated slides. Positive and negative controls were run with each batch of IHC stain. Positive controls unclouded section from invasive breast cancer known to express Ki-67. Negative control staining was obtained by substituting primary antibody with an antibody of irrelevant specificity. Ki-67 score is the percentage of tumor cells showing the nuclear positivity for Ki-67.We used random counting method for counting cells positive for Ki-67 immunostaining. Thus, percentage of tumor cells in 10 randomly chosen fields from most representative invasive areas with minimum 1000 cells were counted. The Ki-67 expression was then correlated with histological subtypes of carcinoma breast.

\section{RESULTS}

Table-1: Age distribution

\begin{tabular}{|l|l|l|}
\hline AGE GROUP (YEARS) & NO. OF CASES & \% AGE \\
\hline $11-20$ & 1 & $1.69 \%$ \\
\hline $21-30$ & 4 & $6.78 \%$ \\
\hline $31-40$ & 14 & $23.73 \%$ \\
\hline $41-50$ & 27 & $45.76 \%$ \\
\hline $51-60$ & 8 & $13.56 \%$ \\
\hline $61-70$ & 5 & $8.47 \%$ \\
\hline GRAND TOTAL & 59 & $100.00 \%$ \\
\hline
\end{tabular}

Table-2: sex distribution

\begin{tabular}{|l|l|l|}
\hline SEX & NO. OF CASES & \% AGE \\
\hline FEMALE & 55 & 93 \\
\hline MALE & 4 & 7 \\
\hline GRAND TOTAL & 59 & 100 \\
\hline
\end{tabular}

Table-3: Type of specimen

\begin{tabular}{|c|c|c|}
\hline TYPE OF SPECIMEN & NO. OF CASES & \% AGE \\
\hline $\begin{array}{c}\text { MODIFIED RADICAL } \\
\text { MASTECTOMY }\end{array}$ & 39 & $66.10 \%$ \\
\hline LUMPECTOMY & 13 & $22.03 \%$ \\
\hline BIOPSY & 7 & $11.87 \%$ \\
\hline GRAND TOTAL & 59 & $100 \%$ \\
\hline
\end{tabular}

Table-4: Histologic subtypes

\begin{tabular}{|c|c|c|c|}
\hline Code & Subtype & No. of Cases & \% AGE \\
\hline 1 & IDC WITH DCIS & 1 & $1.69 \%$ \\
\hline 2 & INVASIV DUCTAL CARCINOMANOS & 52 & $88.14 \%$ \\
\hline 3 & INVASIVE PAPILLARY CARCINOMA & 2 & $3.39 \%$ \\
\hline 4 & INVASIVE LOBULAR CARCINOMA & 1 & $1.69 \%$ \\
\hline 5 & MUCUNOUS CARCINOMA & 1 & 1.69 \\
\hline 6 & IDC WITH SQUAMOUS METAPALSIA & 1 & $1.69 \%$ \\
\hline 7 & METAPLASIC CARCINOMA & 1 & $1.69 \%$ \\
\hline & GRAND TOTAL & 59 & $100.00 \%$ \\
\hline
\end{tabular}


Garima et al; Sch J App Med Sci, Jan, 2021; 9(1): 77-81

Table-5: Association between ki-67 and histologic subtypes

\begin{tabular}{|c|c|c|c|}
\hline CODING & SUBTYPE & No. of CASES & KI-67 SCORE \\
\hline 1 & IDC WITH DCIS & 1 & 18 \\
\hline 2 & INVASIVE DUCTAL CARCINOMA & 52 & 13.46 \\
\hline 3 & INVASIVE PAPILLARY CARCINOMA & 2 & 15 \\
\hline 4 & INVASIVE LOBULAR CARCINOMA & 1 & 11 \\
\hline 5 & MUCINOUS CARCINOMA & 1 & 1 \\
\hline 6 & IDC WITH SQUAMOUS METAPLASIA & 1 & 28 \\
\hline 7 & METAPLASTIC CARCINOMA & 1 & 50 \\
\hline
\end{tabular}

In present study, maximum number of cases was in age group of 41-50 years constituting $45.76 \%$ of call cases while cases were minimum in the age group of $11-20$ year $(1.69 \%)$. Mean age of presentation was 45.71 years. Out of total cases, 93\% were females. Table 3 represents the type of specimen submitted for histopathological and immunohistochemical study. Most of the specimens were of Modified Radical Mastectomy (MRM) constituting $66.10 \%$ followed by lumpectomy specimens $(22.03 \%)$. Biopsy specimens were minimum i.e $11.87 \%$. While males constituted only $7 \%$ of all cases. Present study consists of $88.14 \%$ of invasive ductal carcinoma showing that it is the most common type of breast carcinoma in present study. Invasive papillary carcinoma is second most common subtype and constituted $3.39 \%$ of all cases. Remaining subtype i.e invasive lobular carcinoma, mucinous carcinoma, metaplastic carcinoma, IDC with squamous metaplastic and IDC with DCIS contributed 1.69\% each. Among the breast carcinoma cases, most common subtypes was Invasive ductal carcinoma - not otherwise specified (IDC-NOS) constituting $88.1 \%$ of total cases.

\section{Remaining cases studied were}

1. IDC with DCIS (1.69\%)

2. Invasive papillary carcinoma (3.39\%)

3. Mucinous carcinoma $(1.69 \%)$

4. Invasive lobular carcinoma $(1.69 \%)$

5. Metaplastic carcinoma (1.69\%) and

6. Invasive duct carcinoma with focal squamous metaplasia (1.69).

Table 5 represents Ki67 score in different subtypes of breast carcinoma.Ki67 score was highest in metaplastic carcinoma (60),followed by IDC with squamous metaplasia (28), IDC with DCIS(18), Invasive papillary carcinoma(15), Invasive ductal carcinoma(13.46)and Invasive lobular carcinoma(11)showed Ki-67 score in decreasing order while the score was minimum for mucinous carcinoma(1).

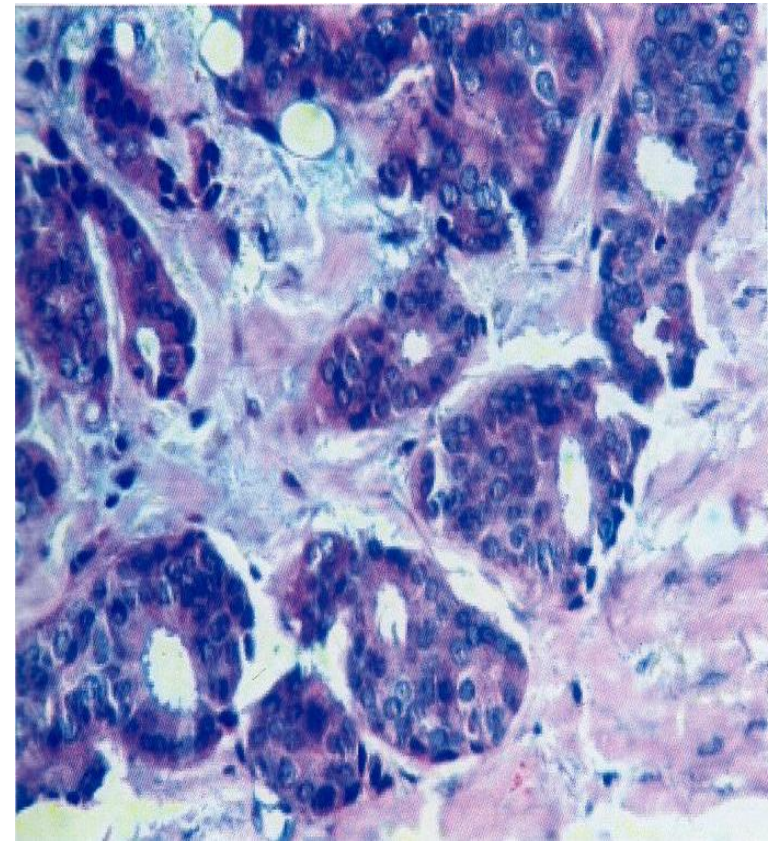

Fig-1: Photomicrograph showing invasive ductal carcinoma (H\&E;x400)

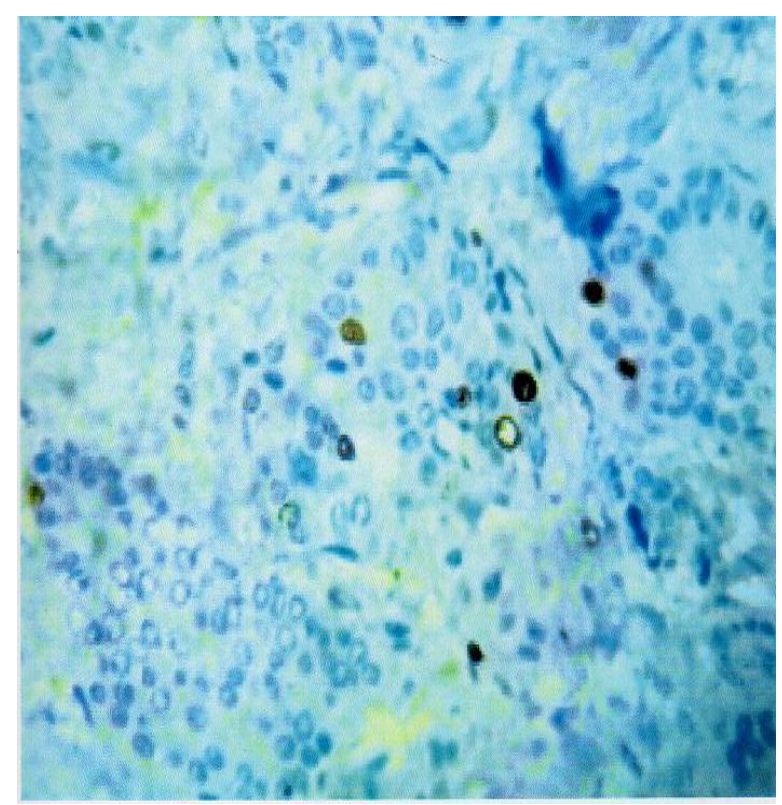

Fig-2: KI-67 Immunostaining in invasive ductal carcinoma $(\mathrm{H} \& \mathrm{E} ; \mathbf{x} 400)$ 


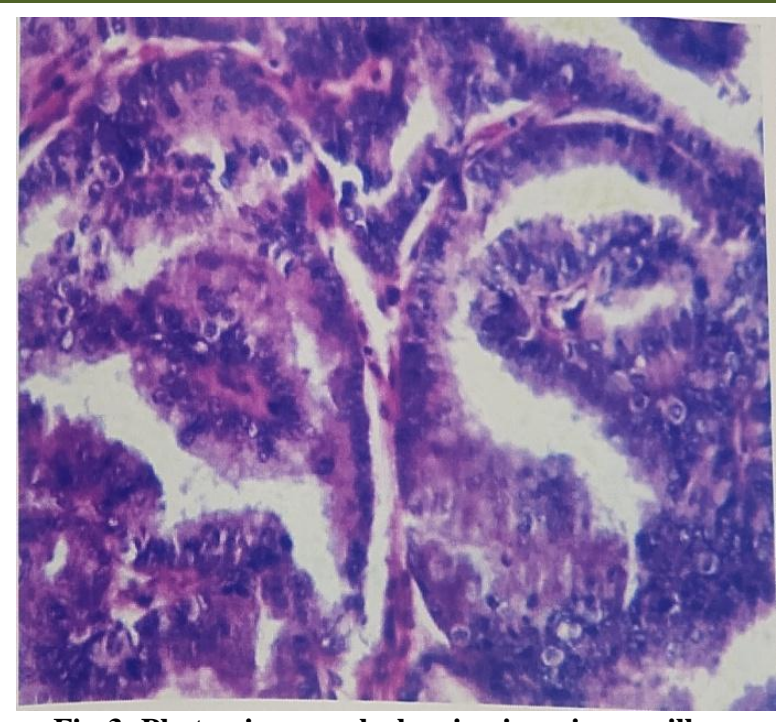

Fig-3: Photomicrograph showing invasive papillary carcinoma (H\&E; $x 400)$

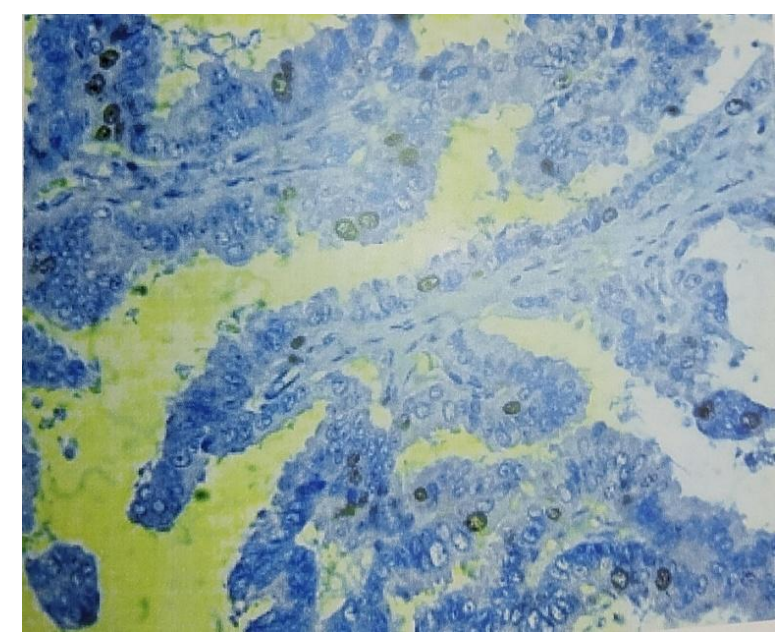

Fig-4: KI-67 Immunostaining in invasive papillary carcinoma (H\&E; $\mathbf{x 4 0 0 )}$

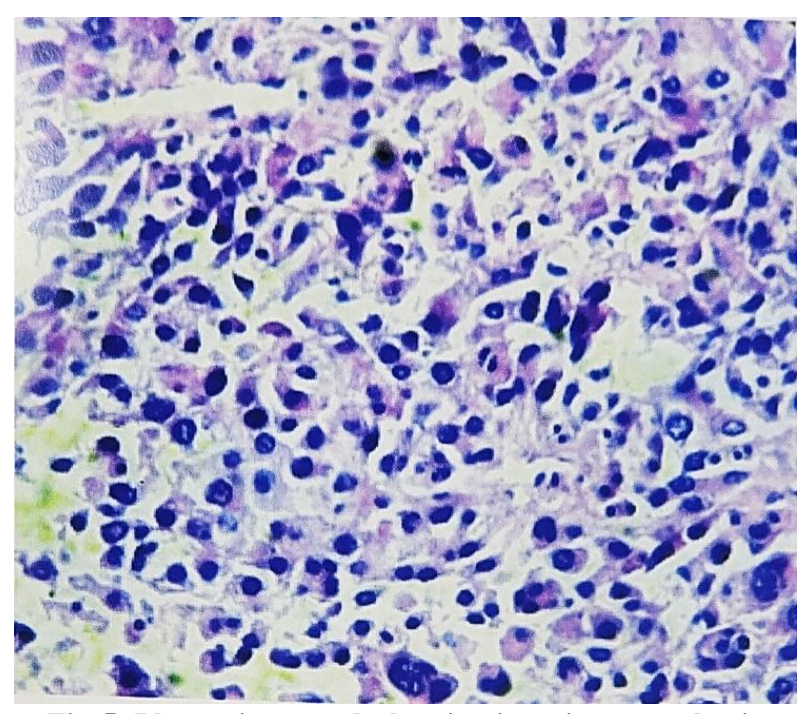

Fig-5: Photomicrograph showing invasive metaplastic carcinoma (H\&E; $x 400)$

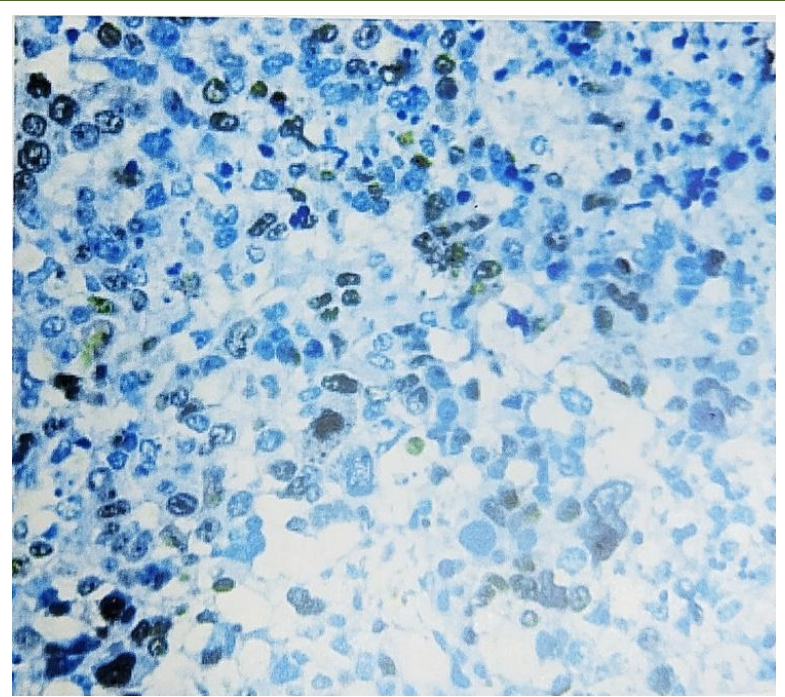

Fig-6 - KI-67 Immunostaining in invasive metaplastic carcinoma (H\&E; $x 400)$

\section{DISCUSSION}

In the study of Grethe Albrektsen et al. [5], ductal tumors, the most common histological type accounted for $81.4 \%$ of all cases, followed by lobular tumors $(6.3 \%)$ and unspecified carcinoma $(5.5 \%)$. Other subtypes accounted for $0.4 \%-1.5 \%$ of the cases Page and Anderson [6] have found invasive duct carcinoma (NOS) to be the commonest to the malignant tumors of breast. In the long term study by Toikkanen et al. from Finland [7], the percentage of various categories of malignant tumors of breast observed was - infiltrating ductal carcinoma $(72.2 \%)$ and lobular carcinoma $(16.1 \%)$. Similarly, in an analysis of breast tumors in a larger series by Eisenberg et al. [8], the investigator reported the incidences of various types of malignant tumors as infiltrating duct carcinoma $-89 \%$, medullary carcinoma $-3.1 \%$ Lobular carcinoma $-59 \%$, other $2.0 \%$.

Clark et al. [9] stated that invasive Lobular carcinoma (ILC) of the breast is far less common than invasive ductal carcinoma (ILC), consisting about 8 $14 \%$ of all breast carcinoma. Lobular carcinoma is more likely to occur in older patients, (with median age of 64.6 years).

One case of papillary carcinoma was also observed in the study. Age at diagnosis was 65 years. Stalsberg and Thomas [10] reported that, while the relative frequency of ductal carcinoma is essentially constant by age, the frequencies of papillary and mucinous carcinomas tend to increase with age. Another case was of metaplastic carcinoma. Age at diagnosis was not mentioned. In the study of Huvos et al. [11], they found that metaplasic breast carcinoma constitute mammary carcinoma. Taylor et al. [12] stated that metaplastic carcinomas are usually seen in women who are more than 50 years old. In our study, single case of mucinous carcinoma was also seen which occurred in 52 year old male. It usually occurs in 
postmenopausal women. It is widely accepted that at least $75 \%$ of the tumour have a mucinous growth pattern. Pure mucinous carcinoma of the male breast is an extremely rare neoplasm [13].

In present study, mean Ki-67 score for various subtypes of breast carcinoma was measured as $13.46 \%$. $15 \%, 1 \%, 28 \%, 11 \%, 18 \%$ and $60 \%$ repectively for IDC (NOS), invasive papillary carcinoma, mucinous carcinoma, metaplastic carcinoma, and invasive lobular carcinoma, IDC with DCIS and IDC with focal squamous metaplasia. Kuenen- Bounmeester et al. [14] studied 34 cases of invasive breast carcinoma and analysed them for heterogeneity of $\mathrm{Ki}-67$ in various histological subtypes. He found ductal carcinomas showing the highest.

Ki-67 reactivity of the 34 , the mucinous the lowest.Mucinous and lobular carcinomas were subdivided according to their dominant growth pattern. Carcinoma with a solid or comedo growth pattern showed the highest proliferative activity. Lelle et al. compared the growth fraction, as determined by Ki-67, of ductal and lobular carcinomas and found lower values in the latter [15].

\section{Conclusion}

Breast carcinoma is the most common malignant tumor in women. Carcinoma of the breast is a truly complex disease with a large intertumoral and intratumoral heterogeneity characteristics leading to uncertain clinical course and varied response to treatment modalities. There are only a few data that have explained the heterogeneity of cells within a tumor; in general, this feature is not fully understood. The translation of molecular approaches into daily clinical practice to support morphological features and immunohistochemical profile is need of time and challenging [16]. Most common histogical subtype in our study was invasive ductal carcinoma followed by invasive papillary carcinoma. Ki67 score was maximum in metaplastic carcinoma followed by IDC with sqouamous metaplasia. Also ductal carcinomas had more ki67 proliferation activity than lobular ones. This agrees with previous studies that anaplastic carcinoma is most aggressive and ductal carcinoms are more aggressive than lobular ones. Size of the present study is small to coclude about the value of $\mathrm{Ki}-67$ in various histological subtypes of breast cancer. Further studies on large samples are required to correlate the Ki-67 to histological subtypes of breast cancer and to consider it as a significant prognostic factor of breast cancer.
1. Tavassoli FA. Pathology and genetics of tumours of the breast and female genital organs. World Hhealth Organization Classification of Tumours. 2003.

2. Wintzer HO, Zipfel I, Schulte- Mönting J, Hellerich $\mathrm{U}$, von Kleist S. Ki- 67 immunostaining in human breast tumors and its relationship to prognosis. Cancer. 1991 Jan 15;67(2):421-8.

3. Wrba F, Chott A, Reiner A, Reiner G, MarkisRitzinger E and Holzner JH. K-67 Immunoreactivity in Breast Carcinomas in Relation to Transferrin Receptor Expression, Estrogen Receptor Status and Morphological Criteria. Oncology, 46(4), 255-259.

4. Alba E, Lluch A, Ribelles N, Anton-Torres A, Sanchez-Rovira P, Albanell J, Calvo L, García-Asenjo JA, Palacios J, Chacon JI, Ruiz A. High proliferation predicts pathological complete response to neoadjuvant chemotherapy in early breast cancer. The oncologist. $2016 \mathrm{Feb}$;21(2):150.

5. Albrektsen G, Heuch I, Thoresen SØ. Histological type and grade of breast cancer tumors by parity, age at birth, and time since birth: a register-based study in Norway. BMC cancer. 2010 Dec 1;10(1):226.

6. Page DL, Dupont WD. Histopathologic risk factors for breast cancer in women with benign breast disease. InSeminars in surgical oncology 1988 (Vol. 4, No. 4, pp. 213-217). New York: John Wiley \& Sons, Inc.

7. Toikkanen SA, Joensuu HE. Prognostic factors and long- term survival in breast cancer in a defined urban population. Apmis. $1990 \mathrm{Jul} ; 98(7-12)$ :100514.

8. Eisenberg AJ, Hajdu SI, Wilhelmus J, Melamed MR, Kinne D. Preoperative aspiration cytology of breast tumors. Acta cytologica. 1986 Mar 1;30(2):135-46.

9. Clark GM, Dressler LG, Owens MA, Pounds G, Oldaker T, McGuire WL. Prediction of relapse or survival in patients with node-negative breast cancer by DNA flow cytometry. New England Journal of Medicine. 1989 Mar 9;320(10):627-33.

10. Stalsberg H, Thomas DB. Age distribution of histologic types of breast carcinoma. International journal of cancer. 1993 Apr 22;54(1):1-7.

11. Huvos AG. Metaplastic breast carcinoma. Rare form of mammary cancer. NY J Med. 1973;73:1078-82.

12. Tylor DB, Adamson R, Ninchin DE. Reading L. Carcinoma of the breast with sarcomotous meteplasia. Australas Radiol. 1994; 38: 262-264.

13. Martinez- Consuegra N, Bawuera-Heredia J, RoblesVidal C, Zumaran-Cuellar O, Oritiz -Hidalgo C. Pure mucinous(colloid) carcinoma of the male breast. An uncommon subtype. Gac Med Mex. 2007; 143(1): 7981.

14. Haagensen CD. Diseases of the Breast (third ed.), W.B. Saunders, Philadelphia. 1986, 250-266.

15. Lelle RJ, Heidenreich W, Stauch G, Gerdes J. The correlation ofgrowth fractions with histologic grading and lymph node status in human mammary carcinoma. Cancer. 1987;59:83-8.

16. Peter S, Lakhani SR. Recent developments in the molecular pathology of breast cancer. Breast Cancer. 2009;98:23-7.

\section{REFERENCES}

